\title{
Measures of Risk on Variability with Application in Stochastic Activity Networks
}

\author{
Yousry H. Abdelkader* \\ Dept. of Math., Faculty of Science, Alexandria University, Alexandria, Egypt. \\ *E-mail: yabdelkader@yahoo.com
}

\begin{abstract}
We propose a simple measure of variability of some of the more commonly used distribution functions in the class of New-Better-than-Used in Expectation (NBUE). The measure result in a ranking of the distributions, and the methodology used is applicable to other distributions in NBUE class beside the one treated here. An application to stochastic activity networks is given to illustrate the idea and the applicability of the proposed measure.
\end{abstract}

Keywords: Alternative Risk measure, Portfolio, Coefficient of Variation, Skewness, Project management, Stochastic activity networks.

\section{Introduction}

An important issue that looms high in the management of real life project is that of risk under conditions of uncertainty. "Risk" is may be used as a synonymous with "Variability", which is best estimated by the variance of the completion time of 'milestone events', including the project completion time, or the project cost, or the resources consumed in its execution or might be R\&D see, e.g., (Elamaghraby, 2005; Wang \&Hwang, 2007; Durbach \& Stewart, 2009). On the other hands, Liu \& Liu (2002) defined the expected value and variance for measuring the portfolio return and the risk, respectively. Therefore, one of the most basic measure of risk is the standard deviation or variance. However, other measures of risk may be considered as well see, e.g., (Yitzhaki, 1982; Shailt \& Yitzhaki, 1989; Konno \& Yamazaki, 1991; Kijima \& Ohnishi, 1993; Duffie \& Pan, 1997; Levy, 1998; Ringuest et al., 2000; Leshno \& Levy, 2002; Tang, 2006; Neiger et al., 2009). Graves \& Ringuest (2009) discussed the well known six decision making methods: 1. Mean-Variance, 2. Mean-Semivariance, 3. Mean-Critical Probability, 4. Stochastic Dominance, 5. Almost Stochastic Dominance, and 6. Mean-Gini. They showed the strength and limitations of each technique, and the relationships between the various methodologies. On the other hand, one would prefer a portfolio return with larger degree of asymmetry when the mean and variance are same. A concept of skewness is introduced by Li et al. (2010) to measure the asymmetry of fuzzy portfolio return. The squared coefficient of variation $[\mathrm{CV}]$ (=variance / mean ) is used to characterize the variability of a distribution see, e.g., (Nuyens \& Wierman, 2008). Distributions with $C V^{2}>1$ are said to have high variability and distributions with $C V^{2}<1$ are said to have low variability.

Most of the above literature discussed and compared measures of risk in portfolio decision making. In this paper, we propose a measure that assists in comparing variances, hence variability. This measure of risk is used to rank many proposed distribution functions and applying it in project management. Besides, it can be applied in portfolio decision making when different distributions are used. The concept of skewness as well as the squared coefficient of variation are also considered. An application to stochastic activity networks (SANs) is given to illustrate the effectiveness of the proposed measure.

Many probability distributions are discussed in literature as representative of a project activity times. To the best of our knowledge, all suggested distributions fall in the class of 'New Better than Used in Expectation (NBUE)' distributions. For the sake of self-containment we state the distributions that are most frequently discussed in treatises on stochastic activity networks, their mean (denoted by $E($.$) or \mu$ ), variance (denoted by $\operatorname{Var}($.$) or \sigma^{2}$ ) and skewness (denoted by $\gamma_{1}=\mu_{3} / \sigma^{3}$, where $\mu_{3}$ is the third central moment and $\sigma$ is the standard deviation).

- The Generalized Beta distribution with probability density function

$$
f(x)=\frac{1}{(b-a)^{k_{1}+k_{2}-1} B\left(k_{1}, k_{2}\right)}(x-a)^{k_{1}-1}(b-x)^{k_{2}-1}, \quad a \leq x \leq b,
$$


where $B\left(k_{1}, k_{2}\right)$ is the complete Beta function. $B\left(k_{1}, k_{2}\right)=\Gamma\left(k_{1}\right) \Gamma\left(k_{2}\right) / \Gamma\left(k_{1}+k_{2}\right)$, and $\Gamma(k)=(k-1)$ ! if $k$ is a positive integer, and $\Gamma(k)=\int_{0}^{\infty} t^{k-1} e^{-t} d t$ if $k>0$. The mean, the variance and skewness are given by

$$
\begin{aligned}
& E(X)=a+(b-a) \frac{k_{1}}{k_{1}+k_{2}}, \quad \operatorname{Var}(X)=(b-a)^{2} \frac{k_{1} k_{2}}{\left(k_{1}+k_{2}\right)^{2}\left(k_{1}+k_{2}+1\right)}, \\
& \gamma_{1}=\frac{2\left(k_{2}-k_{1}\right) \sqrt{\left(1+k_{1}+k_{2}\right)}}{\sqrt{\left(k_{1} k_{2}\right)}\left(2+k_{1}+k_{2}\right)} .
\end{aligned}
$$

The beta distribution with $k_{1}=2$ and $k_{2}=3$ is discussed by Golenko (1989).

- The Beta-PERT distribution, so designated because it was the distribution initially proposed by Malcolm et al. (1959) in their seminal paper on PERT (Program Evaluation and Review Technique). The proposed mean and variance of activity time distribution are given by

$$
E(X)=\frac{a+4 m+b}{6} \quad \text { and } \quad \operatorname{Var}(X)=\left(\frac{b-a}{6}\right)^{2},
$$

where $a, m$, and $b$ are; respectively, the 'optimistic', 'most likely' and 'pessimistic' times of the activity. Equation (3) holds when $k_{1}=k_{2}=4$, or $k_{1}=3+\sqrt{2}$ and $k_{2}=3-\sqrt{2}$, or $k_{1}=3-\sqrt{2}$ and $k_{2}=3+\sqrt{2}$ in (2) above. The latter two special cases satisfy $k_{1}+k_{2}=6$, see (Elmaghraby, 1977, p236). The skewness will be $0, \frac{-1}{\sqrt{2}}$ and $\frac{1}{\sqrt{2}}$ in the above three cases respectively.

- The Uniform distribution, defined on the range $x \in[a, b]$ is discussed by Kleindorfer (1971), with probability density function

$$
f(x)=\frac{1}{b-a}, \quad a \leq x \leq b,
$$

with mean, variance and skewness are given by

$$
E(X)=\frac{a+b}{2}, \quad \operatorname{Var}(X)=\frac{(b-a)^{2}}{12} \quad \text { and } \quad \gamma_{1}=0 .
$$

- The Triangular distribution discussed by Williams (1992) and Johson (1997), with probability density function

$$
f(x)= \begin{cases}\frac{2(x-a)}{(m-a)(b-a)}, & a \leq x \leq m \\ \frac{2(b-x)}{(b-a)(b-m)}, & m<x \leq b\end{cases}
$$

where the range of the random variable (r.v.) is defined on the interval $[a, b], m \in[a, b]$ and $m$ stands for the mode. The mean, variance and skewness are given by

$$
E(X)=\frac{a+m+b}{3}, \quad \operatorname{Var}(X)=\frac{1}{18}\left(a^{2}+b^{2}+m^{2}-a b-a m-b m\right)
$$

and

$$
\gamma_{1}=\frac{\sqrt{2}(a+b-2 m)(2 a-b-m)(a-2 b+m)}{5\left(a^{2}+b^{2}+m^{2}-a b-a m-b m\right)} .
$$

- The exponential distribution with parameter $\lambda$ is discussed by many authors ( Kambrowski ,1985 and Kulkarni \& Adlakha, 1986) with probability density function

$$
f(x)=\lambda e^{-\lambda x}, \quad x \geq 0, \quad \lambda>0,
$$

with mean, variance and skewness are given by

$$
E(X)=\frac{1}{\lambda}, \quad \operatorname{Var}(X)=\frac{1}{\lambda^{2}} \quad \text { and } \quad \gamma_{1}=2 .
$$

- The Erlang distribution, discussed by Bendell et al. (1995) and their work is generalized by Abdelkader (2003) 
with probability density function

$$
f(x)=\frac{\lambda^{k}}{\Gamma(k)} e^{-\lambda x} x^{k-1}, \quad x \geq 0, \lambda, k>0 .
$$

The mean, variance and skewness are given by

$$
E(X)=\frac{k}{\lambda}, \quad \operatorname{Var}(X)=\frac{k}{\lambda^{2}} \quad \text { and } \quad \gamma_{1}=\frac{2}{\sqrt{k}} .
$$

The remainder of this paper is organized as follows. The main definitions and preliminaries are given in Section 2. Section 3 presents a measures of variability to rank the suggested distribution functions. Besides two other measures which can be used in some special applications. Section 4 is devoted to introduce an application to stochastic activity networks. Finally, concluding remarks are drawn in Section 5.

\section{Definitions and Preliminaries}

We begin by introducing some required definitions. The following definitions and proposition are presented in Ross (1983).

Definition 1. A nonnegative r.v. $X$ with finite mean $\mu$ and probability distribution function $F$ is said to be NBUE ( New Better than Used in Expectation) if, for all $x>0$

$$
\int_{x}^{\infty} \frac{\bar{F}(y)}{\bar{F}(x)} d y \leq \mu,
$$

where $\bar{F}(x)=1-F(x)>0$.

A random variable is said to be NBUE if its distribution function has that property

Definition 2. If $X$ and $Y$ are non-negative r.v.'s such that $E(X)=E(Y)$, then the r.v. $X$ is said to be more variable than $Y$, written $X \geq_{v} Y$, if and only if $E[h(X)] \geq E[h(Y)]$ for all increasing and convex functions $h$.

Definition 3. If the r.v.'s $X$ and $Y$ have the distributions $F$ and $G$, respectively, then $X$ is stochastically larger than $Y$, written $X \geq_{s t} Y$, if

$$
\bar{F}(a) \geq \bar{G}(a), \quad \text { for all } a
$$

where $\bar{G}(x)=1-G(x)$.

Proposition 1. If $F(x)$ is an NBUE distribution having mean $\mu$, then

$$
F \leq_{v} \exp (\mu)
$$

Where $\exp (\mu)$ is the exponential distribution with mean $\mu$.

The above proposition states that the exponential distribution has maximal variability in the class of NBUE distributions.

The following Theorem is introduced by Li (2002).

Theorem 1. Suppose $X$ is NBUE with finite mean $\mu$, then for all $k=1,2, \ldots$
(i) $E\left(X^{k}\right) \leq k \mu E\left(X^{k-1}\right)$,
(ii) $E\left(X^{k}\right) \leq k ! \mu^{k}$.

\section{Main Results}


In this section we introduce the proposed measure in Proposition 2 and its properties are summarized in corollaries 1 and 2. The variability relationships among the proposed distribution are introduced in Theorems 2 and 3 . Two alternative measures of variability are also discussed.

Proposition 2. For any NBUE probability distribution function $F(x)$ with $E(X)=\mu$ and $\operatorname{Var}(X)=\sigma^{2}$, then

$$
\Delta(F) \square \mu^{2}-\sigma^{2} \geq 0
$$

where $\square$ stands for the definition of $\Delta(F)$.

Proof. Set $k=2$ in part (ii) of Theorem 1, to get

$$
E\left(X^{2}\right) \leq 2 \mu^{2}
$$

which is equivalent to

$$
\Delta(F)=\mu^{2}-\left(E\left(X^{2}\right)-\mu^{2}\right) \geq 0 .
$$

This completes the proof.

Corollary 1. A nonnegative r.v. $X$ has a maximal variability in the class of NBUE if $\Delta(F)=0$.

This result follows from the fact that the exponential distribution has its $\mu^{2}=\sigma^{2}$. It also immediately follows that for all other distributions in the class NBUE $\Delta(F)>0$.

Corollary 2. The most variability occurs when the value of $\Delta(F)=0$, and for all the class of NBUE the value of $\Delta(F)>0$.

The following Theorems summarize the variability relationships among the following distributions: the exponential, Erlang, Uniform, Triangular, Beta and Beta(PERT). We denote the random variables corresponding to the above distributions respectively by $X_{\text {exp }}, X_{E}, X_{U}, X_{T}, X_{\text {Beta }}$ and $X_{P E R T}$.

Theorem 2. If all the distributions stated above are symmetric about their means, then

$$
\operatorname{Var}\left(X_{U}\right) \geq \operatorname{Var}\left(X_{T}\right) \geq \operatorname{Var}\left(X_{B e t a(3,3)}\right) \geq \operatorname{Var}\left(X_{\text {PERT }}\right) \text {. }
$$

Proof. Under the assumption that all distributions are symmetric about their mean implies the four distributions have the same mean. This, in turn, implies that for the Triangular and PERT the mode $m=(a+b) / 2$, and that for the Beta we must have $k_{1}=k_{2}=3$ or 4 . It is sufficient to show, by Corollaries 1 and 2 , that the variances of the corresponding r.v.'s bear the same inequalities to each other. It is easy to demonstrate that since all means $=(a+b) / 2$, by substitution in (2)-(5),

$$
\begin{aligned}
& \operatorname{Var}\left(X_{U}\right)=\frac{(a-b)^{2}}{12}, \operatorname{Var}\left(X_{T}\right)=\frac{(a-b)^{2}}{24}, \operatorname{Var}\left(X_{\text {Beta }(3,3)}\right)=\frac{(a-b)^{2}}{28} \\
& \operatorname{Var}\left(X_{\text {Beta }(4,4)}\right)=\operatorname{Var}\left(X_{\text {PERT }}\right)=\frac{(a-b)^{2}}{36}
\end{aligned}
$$

and the ranking of (13) is validated.

For other values of $k_{1}$ and $k_{2}$, we discuss the following two cases:

- (i) For $k_{1}=k_{2}=2$ or 1, the inequality (13) changes to

$$
\operatorname{Var}\left(X_{U}\right) \geq \operatorname{Var}\left(X_{\text {Beta }}\right) \geq \operatorname{Var}\left(X_{T}\right) \geq \operatorname{Var}\left(X_{\text {PERT }}\right) \text {. }
$$

- (ii) For $k_{1}=k_{2}=5$, the inequality (13) changes to 


$$
\operatorname{Var}\left(X_{U}\right) \geq \operatorname{Var}\left(X_{T}\right) \geq \operatorname{Var}\left(X_{\text {PERT }}\right) \geq \operatorname{Var}\left(X_{\text {Beta }}\right),
$$

and hence the proof.

Remark 1. According to the notation of Proposition 2, we can rewrite the statement of Theorem 2 as

$$
\Delta\left(F_{U}\right) \geq \Delta\left(F_{T}\right) \geq \Delta\left(F_{\text {Beta }}\right) \geq \Delta\left(F_{\text {PERT }}\right),
$$

where

$$
\Delta\left(F_{U}\right)=\mu^{2}-\operatorname{Var}\left(X_{U}\right), \quad \Delta\left(F_{T}\right)=\mu^{2}-\operatorname{Var}\left(X_{T}\right), \quad \Delta\left(F_{B e t a}\right)=\mu^{2}-\operatorname{Var}\left(X_{B e t a}\right),
$$

and

$$
\Delta\left(F_{\text {PERT }}\right)=\mu^{2}-\operatorname{Var}\left(X_{\text {PERT }}\right) .
$$

The following Theorem will be discussed, under the same assumption of Theorem 2, for the Erlang distribution when $k=2,3,4$ and 5 . We exclude $k=1$, since the Erlang distribution in this case is reduced to the exponential distribution.

Theorem 3. If $E\left(X_{U}\right)=E\left(X_{E}\right)=E\left(X_{T}\right)=\mu$,

$$
\operatorname{Var}\left(X_{\text {exp }}\right) \geq \operatorname{Var}\left(X_{E}\right) \geq \operatorname{Var}\left(X_{U}\right) \geq \operatorname{Var}\left(X_{T}\right) .
$$

Proof. According to the Proposition 1 and Corollary 1 the exponential distribution has a maximal variability in the class of NBUE distributions; hence the inequality ' $\leq$ ' is true for any other distributions. This establishes the leftmost inequality. Let

$$
\Delta\left(F_{U}\right)=\mu^{2}-\operatorname{Var}\left(X_{U}\right), \Delta\left(F_{E}\right)=\mu^{2}-\operatorname{Var}\left(X_{E}\right) \text { and } \Delta\left(F_{T}\right)=\mu^{2}-\operatorname{Var}\left(X_{T}\right),
$$

be the measures of variability of the Uniform, Erlang and Triangular distributions; respectively. As indicated in the proof of Theorem 2, equality of the means implies that the mode $m$ of the Triangular distribution is exactly mid-way between $a$ and $b$, i.e., $m=(a+b) / 2$. To prove the theorem it is required to show that

$$
\Delta\left(F_{E}\right) \leq \Delta\left(F_{U}\right) \leq \Delta\left(F_{T}\right)
$$

where

$$
\begin{aligned}
& \Delta\left(F_{U}\right)=\frac{(a+b)^{2}}{4}-\frac{(b-a)^{2}}{12}, \\
& \Delta\left(F_{E}\right)=\frac{k^{2}}{\lambda^{2}}-\frac{1}{k} \frac{k^{2}}{\lambda^{2}}=\frac{(a+b)^{2}}{4}-\frac{(a+b)^{2}}{4 k}, \\
& \Delta\left(F_{T}\right)=\frac{(a+b)^{2}}{4}-\frac{(b-a)^{2}}{24} .
\end{aligned}
$$

It is easy to see that the inequality (17) is hold when $k=2$ and 3.

For $k=4$, the inequality (17) is true when

$$
a b \geq \frac{(b-a)^{2}}{12} \text { or } a b \geq \operatorname{Var}\left(X_{U}\right) \text { and } a, b>0 .
$$

For $k=5$, the inequality (17) is true when

$$
a b \geq 2 \frac{(b-a)^{2}}{12} \text { or } a b \geq 2 \operatorname{Var}\left(X_{U}\right) \text { and } a, b>0 .
$$

The proof is completed.

Corollary 3. The above two Theorems showed that

For $k_{1}=k_{2}=2$ 
For $k_{1}=k_{2}=3$

$$
\operatorname{Var}\left(X_{\exp }\right) \geq \operatorname{Var}\left(X_{E}\right) \geq \operatorname{Var}\left(X_{U}\right) \geq \operatorname{Var}\left(X_{\text {Beta }(2,2)}\right) \geq \operatorname{Var}\left(X_{T}\right) \geq \operatorname{Var}\left(X_{\text {PERT }}\right) .
$$

$$
\operatorname{Var}\left(X_{\text {exp }}\right) \geq \operatorname{Var}\left(X_{E}\right) \geq \operatorname{Var}\left(X_{U}\right) \geq \operatorname{Var}\left(X_{T}\right) \geq \operatorname{Var}\left(X_{B e t a(3,3)}\right) \geq \operatorname{Var}\left(X_{\text {PERT }}\right) .
$$

For $k_{1}=k_{2}=5$

$$
\operatorname{Var}\left(X_{\exp }\right) \geq \operatorname{Var}\left(X_{E}\right) \geq \operatorname{Var}\left(X_{U}\right) \geq \operatorname{Var}\left(X_{T}\right) \geq \operatorname{Var}\left(X_{P E R T}\right) \geq \operatorname{Var}\left(X_{B e t a(5,5)}\right) .
$$

Remark 2. Haha (2008) showed that the uniform distribution has more variability and the above Theorems showed that the variability of the uniform distribution is less than the exponential and Erlang distributions.

\subsection{Alternative Measures of Variability}

Besides the measures mentioned in Graves \& Ringuest (2009), another two measures are also proposed for comparing between distributions.

\section{The First measure}

The following Lemma and the consequence Proposition are presented in Ross (1983).

Lemma 1. Let $F$ and $G$ be continuous distribution functions. If $X$ has distribution $F$, then the r.v. $G^{-1}(F(X))$ has distribution $G$.

Proposition 3. Let $F$ and $G$ are distributions such that $\bar{F}(a) \geq \bar{G}(a)$, then there exist r.v.'s $X$ and $Y$ having distributions $F$ and $G$ respectively such that

$$
P(X \leq Y)=1 .
$$

This means that, if $X \geq_{s t} Y$, then there exist r.v.'s $X_{1}$ and $Y_{1}$ having the same distributions of $X$ and $Y$ such that $X_{1}$ is at least as larger as $Y_{1}$ with probability one.

\section{The Second measure}

This measure is due to Mood et al. (1974) page 74, which characterizes the distribution by the variance.

Suppose that $f_{1}(x)$ and $f_{2}(x)$ are two probability density functions with the same mean $\mu$ such that

$$
\int_{\mu-c}^{\mu+c}\left(f_{1}(x)-f_{2}(x)\right) d x \geq 0,
$$

for every value of $c$, then

$$
\sigma_{1}^{2}<\sigma_{2}^{2}
$$

which means that, the variance $\sigma_{1}^{2}$ in the first density is smaller than the variance $\sigma_{2}^{2}$ in the second density. The converse of inequality (24) is not true. That is, if $\sigma_{1}^{2}<\sigma_{2}^{2}$, we can not conclude that the

corresponding densities satisfy the inequality (24) for all values of $c$.

\section{Applications in SANs}

This section introduces an application to stochastic activity networks by applying Theorems 2 and 3. The following worked example demonstrates the comparison between the variances of the proposed distribution which are discussed in the paper.

Example The network in Fig.1 is taken from Elmaghraby (1977 p 314). The activity times and tasks description of 
ship-boiler repair are shown in Table 1. The three durations attached to each activity are the optimistic "a", most likely " $\mathrm{m}$ ", and pessimistic " $\mathrm{b}$ " estimates, obtained by asking the experts. We modified the most likely time to be $(=(a+b) / 2)$ to agree with the equality of the means for all distributions. The mean project completion time for all distributions is equal to 47.75 . Table 2 shows the squared coefficient of variation (SCV) of each critical activity. The SCV for the exponential distribution is equal to 1 and the SCV for Erlang distribution when $k=2,3,4$ and 5 are $0.5,0.333,0.25$ and 0.2 , respectively. Table 3 summarizes the variances, skewness and the sum squared coefficient of variation (SSCV) obtained from the proposed distributions. The SSCV for the exponential distribution is equal to 9 and for the Erlang distribution when $k=2,3,4$ and 5 are equal to $4.5,3,2.25$ and 2 , respectively.

Remark 3. In Table 2, we note that the SCV for the activities 15 and 18 are greater than the SCV of Erlang distribution when $k=4$ and 5 . The reason for that is both activities violate the equations (21)

and (22), that is, $a>0$.

Remark 4. From Table 3 we note that

$$
\begin{aligned}
& \operatorname{Var}\left(X_{\text {exp }}\right) \geq \operatorname{Var}\left(X_{E}\right) \geq \operatorname{Var}\left(X_{U}\right) \geq \operatorname{Var}\left(X_{T}\right) \geq \operatorname{Var}\left(X_{B e t a(3,3)}\right) \geq \operatorname{Var}\left(X_{\text {PERT }}\right), \\
& \operatorname{Var}\left(X_{\text {exp }}\right) \geq \operatorname{Var}\left(X_{E}\right) \geq \operatorname{Var}\left(X_{U}\right) \geq \operatorname{Var}\left(X_{B e t a(2,2)}\right) \geq \operatorname{Var}\left(X_{T}\right) \geq \operatorname{Var}\left(X_{\text {PERT }}\right), \\
& \operatorname{Var}\left(X_{\text {exp }}\right) \geq \operatorname{Var}\left(X_{E}\right) \geq \operatorname{Var}\left(X_{U}\right) \geq \operatorname{Var}\left(X_{T}\right) \geq \operatorname{Var}\left(X_{P E R T}\right) \geq \operatorname{Var}\left(X_{B e t a(5,5)}\right) .
\end{aligned}
$$

Remark 5. The coefficient of skewness which is shown in Table 3 ranking the exponential and Erlang distributions for different values of $k$. The zero skewness for the other distributions came from the symmetry assumption of those distributions.

In making decisions about which project to include in a real industrial cases, one should evaluate the risk. Many R\&D and IT projects fail in either the marketing stage or the implementation stage. The results of this paper including the above example provide an authoritative source to engineers or managers who need to choose the appropriate distribution for evaluating risk in their decision making. In all distributions discussed in this paper we compute the variance, the skewness and the squared coefficient of variation. Based on these measures the engineers or managers would select an appropriate portfolio.

\section{Conclusion}

In this paper, a simple measure is used to rank the distribution functions. The proposed distributions which are discussed are: the exponential, Erlang, Uniform, Triangular, Beta and Beta (PERT) distribution with different values of $k_{1}$ and $k_{2}$. All suggested distributions fall in the class of NBUE distributions and considered to be symmetric about their mean. The ranking of the distributions are discussed in Theorems 2 and 3. Corollary 3 summarizes the final results. Two alternative measures are stated for comparing the variability between the distributions. The second measure may be used when the graphical representation is considered. The condition, $\sigma_{1}^{2}<\sigma_{2}^{2}$, in the third measure is only evident that $f_{1}(x)$ has more area near the mean than $f_{2}(x)$, at least for certain intervals about the mean. Finally, an application to stochastic activity networks is introduced. The example network which is shown in the application verified the results of Theorems 1 and 2. On the other hand, in portfolio selection theory (see, e.g. Markowitz, 1952 1959) we can consider the portfolio return as a constant for all proposed distributions and the risk is varying. The issue that may require further investigation is the development of a measure do not restrict the assumption that the distributions are symmetric about the mean. Also, more distributions may be included for future research.

\section{Acknowledgements}

The author would like to thank Prof. Salah E. Elmaghraby from North Carolina State University, USA for his remarks that improved the paper. 


\section{References}

Abdelkader, Y.H. (2003), "Erlang distributed activity times in stochastic activity networks", Kybernetika 39(3), 347358.

Bendell, A., Solomon, D., \& Carter, J.M. (1995), “Evaluating project completion times when activity times are Erlang distribution", Journal of Operational Research society, 46, 867-882.

Durbach, I.N, \& Stewart, T.J. (2009), "Using the expected values to simplify decision making under uncertainty", Omega 37, 312-330.

Duffie, D., \& Pan, J. (1997), “An overview of value at risk”, The Journal of Derivatives, 4(3), 7-49.

Elmaghraby, S.E. (2005), "On the fallacy of averages in project risk management", European Journal of Operational Research 165, 307-313.

Elmaghraby, S.E. (1977), “Activity networks: Project planning and control by network models”, Wiley, New York.

Golenko (Ginzburg), D.I. (1989), "A new approach to the activity-time distribution in PERT", Journal of Operational Research society 40, 389-393.

Graves, S.B., \& Ringuest, J.L. (2009), "Probabilistic dominance criteria for comparing uncertain alternatives: A tutorial”, Omega 37, 346-357.

Hahn, E.D. (2008), " Mixture densities for project management activity times: A robust approach to PERT", European Journal of Operational Research 188, 450-459.

Johnson, D. (1997), "The triangular distribution as a proxy for beta distribution in risk analysis", The Statistician 46(3), 387-98.

Kamburowski, J. (1985), “An upper bound on the expected completion time of PERT networks", European Journal of Operational Research,21, 206-212.

Kijima, M., \& Ohnishi, M. (1993), "Mean-risk analysis of risk aversion and wealth effects on optimal portfolios with multiple investment opportunities", Annals of Operations Research 45, 147-163.

Kleindorfer, G.B. (1971), "Bounding distributions for a stochastic acyclic network", Operations Research 19(7), 1586-1601.

Konno, H., \& Yamazaki, H. (1991), “A mean-absolute deviation portfolio optimization model and its application to Tokyo stock market”, Management Science 37, 519-531.

Kulkarni, V.G., \& Adlakha, V.G. (1986), "Markov and Markov regenerative PERT networks", Operations Research 34(5), 769-781.

Leshno, M., \& Levy, H. (2002), "Preferred by 'all' and preferred by 'most' decision makers: almost stochastic dominance, "Management Science 48(8), 1074-1085.

Levy, H. (1998), "Stochastic dominance: investment decision making under uncertainty", Boston, Kluwer.

Li, X. (2002), “A new interpretation of NBUE property of life distribution with some applications", Chinese Journal of Applied Probability and Statistics 16(1), 67-72.

Li, X., Qin, \& Z., Kar, S. (2010) , "Mean-variance-skewness model for portfolio selection with fuzzy returns", European Journal of Operational Research 202, 239-247.

Liu, B. \& Liu, Y.K. (2002), "Expected value of fuzzy variable and fuzzy expected value models", IEEE Transactions on Fuzzy System 10(4), 445-450.

Malcolm, D.G., Roseeboom, J.H., Clark, C.E, \& Fazar, W. (1959), “Application of technique for research and development program evaluation”, Operations Research 7, 646-669.

Markowitz, H. (1952), “ Portfolio selection”, Journal of Finance 7, 77-91.

Markowitz, H. (1959), "Portfolio selection: Efficient Diversification of Investments", Wiley, New York.

Mood, A.M., Graybill, F.A., \& Boes, D.C. (1974), "Introduction to the theory of statistics", McGraw-Hill, London.

Neiger, D., Rotaru, K., \& Churilvo, L. (2009), “ Supply chain risk identification with value-focused process 
engineering”, Journal of Operations Management 27, 154-168.

Nuyens, M., \& Wierman, A. (2008), “The foreground-Background queue: A survey", Performance Evaluation 65, 286-307.

Ringuest, J.L., Graves, S.B, \& Case, R.H. (2000), “Conditional stochastic dominance in R\&D portfolio selection”, IEEE Transaction on Engineering Management 74(4), 478-484.

Ross, S.M. (1983). Stochastic Process", John Wiley \& Sons, New York.

Shalit, H., \& Yitzhaki, S. (1989), "Evaluating the mean gini approach to portfolio selection", The International Journal of Finance 1(2), 15-31.

Tang, C.S. (2006), "Perspective in supply chain risk management", International Journal of Production Economics, 103(2), 451-488.

Wang, J., \& Hwang, W.L. (2007), “A fuzzy set approach for R\&D portfolio selection using real options valuation model", Omega, 35(3), 247-257.

Williams, T.W. (1992), "Practical use of distributions in network analysis", Journal of Operational Research society 43, 265-270.

Yitzhaki, S. (1982), “Stochastic dominance and Gini's mean difference”, American Economic Review 72(1), $178-185$.

Yousry H Abdelkader is Associate professor in Mathematics Department, Faculty of Science, Alexandria University, Egypt. He is now working at Mathematics Department, Faculty of Science, Dammam University, KSA. $\mathrm{He}$ is eared his baccalaureate and Master degrees form Alexandria university, Egypt and a Master degree from Northeastern University, Boston, USA. He got his doctorate degree (2000) from Alexandria University, Egypt. His area of interest are: Stochastic PERT networks, Order Statistics, Queueing Theory and Reliability Theory. He is a referee in many international journals. Dr. Abdelkader has contributed significantly in the area of Stochastic PERT networks and Order statistics. He has published many research articles in various journals such as: European Journal of Operational Research, Annals of Operations Research, Kybernetika, Statistics and Probability Letter, Statistica, Journal of Indian Society of Statistical and Operations Research, Journal of Computational and Applied Mathematics, Statistical Papers, Statistical Methods \& Applications, and many others. 
European Journal of Business and Management ISSN 2222-1905 (Paper) ISSN 2222-2839 (Online)

Vol 4, No.8, 2012

Table 1. Activity times and Description

\begin{tabular}{llll}
\hline Activity & Describtion & Predecessor & Duration \\
\hline 1 & Initial Hydrostatic Test & - & $1,3,5$ \\
2 & Remove air registers & - & $0,1.5,3$ \\
3 & Repair under boiler & - & $14,24.5,35$ \\
4 & Remove drum internals & 1 & $0.5,1.75,3$ \\
5 & Rag for chemical cleaning & 1 & $5,11,17$ \\
6 & Clean and repair air register assemblies & 2 & $10,15,20$ \\
7 & Repair drum internals & 4 & $5,11.5,18$ \\
8 & Remove refractory material & 1,2 & $4,7,10$ \\
9 & Repair inner air casing & 8 & $1,7.5,14$ \\
10 & Exploratory block & 4,8 & $7,12.5,18$ \\
11 & Retube and poll & 10 & $4,8,12$ \\
12 & Repair outer air casing & 9 & $1,5.5,10$ \\
13 & Rebrick & 9,11 & $5,9.5,14$ \\
14 & Chemically clean & 5,11 & $4,6,8$ \\
15 & Preliminary hydrostatic test & 14 & $0,7,14$ \\
16 & Install drum internals & 7,15 & $1,2,3$ \\
17 & Install air registers & 6,13 & $0.5,1.75,3$ \\
18 & Final hydrostatic tests & 16 & $0,1.5,3$ \\
19 & Install plastic refractory & 17,18 & $0.5,0.75,1$ \\
\hline
\end{tabular}

Table 2. The squared coefficient of variation of the critical activities for the proposed distributions

\begin{tabular}{|l|l|l|l|l|l|l|}
\hline CA & $\mathrm{U}$ & $\mathrm{B}(2,2)$ & $\mathrm{T}$ & $\mathrm{B}(3,3)$ & $\mathrm{B}(4,4)$ & $\mathrm{B}(5,5)$ \\
\hline 1 & 0.148 & 0.088 & 0.074 & 0.063 & 0.049 & 0.040 \\
8 & 0.061 & 0.036 & 0.030 & 0.026 & 0.020 & 0.016 \\
10 & 0.064 & 0.038 & 0.032 & 0.027 & 0.021 & 0.017 \\
11 & 0.083 & 0.050 & 0.041 & 0.035 & 0.027 & 0.022 \\
14 & 0.037 & 0.022 & 0.018 & 0.015 & 0.012 & 0.010 \\
15 & 0.333 & 0.200 & 0.166 & 0.142 & 0.111 & 0.090 \\
16 & 0.083 & 0.050 & 0.041 & 0.035 & 0.027 & 0.022 \\
18 & 0.333 & 0.200 & 0.166 & 0.142 & 0.111 & 0.090 \\
19 & 0.037 & 0.022 & 0.018 & 0.015 & 0.012 & 0.010 \\
\hline
\end{tabular}


European Journal of Business and Management

Where, CA denotes to the Critical Activity, $\mathrm{U}$ denotes to the Uniform distribution, $\mathrm{T}$ denotes to the Triangular distribution and $\mathrm{B}(.,$.$) denotes to the Beta distribution for different values.$

Table 3. The variance, skewness and SSCV of proposed distributions

\begin{tabular}{|l|l|l|l|}
\hline Distribution & Variance & Skewness & SSCV \\
\hline Exponential & 370.0625 & 2 & 9 \\
Erlang(k=2) & 185.03 & 1.414 & 4.5 \\
Erlang(k=3) & 123.35 & 1.155 & 3 \\
Erlang(k=4) & 92.515 & 1 & 2.25 \\
Erlang(k=5) & 74.013 & 0.8944 & 1.8 \\
Uniform=Beta(1,1) & 38.519 & 0 & 1.179 \\
Beta(2,2) & 23.113 & 0 & 0.706 \\
Triangular & 19.262 & 0 & 0.586 \\
Beta(3,3) & 16.508 & 0 & 0.5 \\
PERT=Beta(4,4) & 12.839 & 0 & 0.393 \\
Beta(5,5) & 10.505 & 0 & 0.317 \\
\hline
\end{tabular}

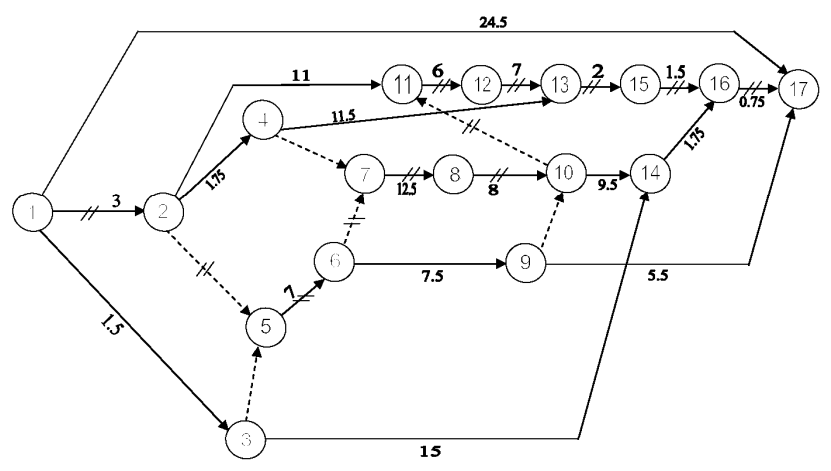

Fig. 1 The mean of each activity is indicated on each arc and the critical path is shown in the network 
This academic article was published by The International Institute for Science, Technology and Education (IISTE). The IISTE is a pioneer in the Open Access Publishing service based in the U.S. and Europe. The aim of the institute is Accelerating Global Knowledge Sharing.

More information about the publisher can be found in the IISTE's homepage: http://www.iiste.org

The IISTE is currently hosting more than 30 peer-reviewed academic journals and collaborating with academic institutions around the world. Prospective authors of IISTE journals can find the submission instruction on the following page: http://www.iiste.org/Journals/

The IISTE editorial team promises to the review and publish all the qualified submissions in a fast manner. All the journals articles are available online to the readers all over the world without financial, legal, or technical barriers other than those inseparable from gaining access to the internet itself. Printed version of the journals is also available upon request of readers and authors.

\section{IISTE Knowledge Sharing Partners}

EBSCO, Index Copernicus, Ulrich's Periodicals Directory, JournalTOCS, PKP Open Archives Harvester, Bielefeld Academic Search Engine, Elektronische Zeitschriftenbibliothek EZB, Open J-Gate, OCLC WorldCat, Universe Digtial Library, NewJour, Google Scholar

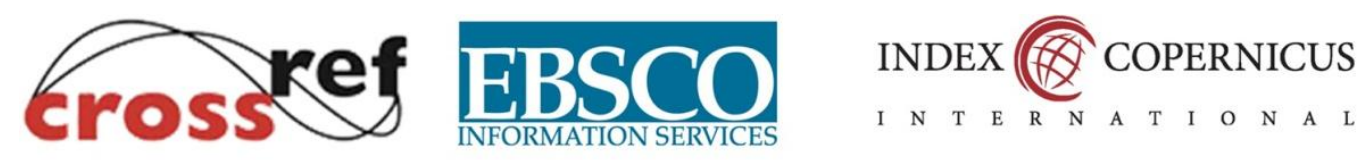

\section{Ounachener}

JournalTOCs

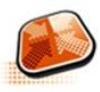

PKP | PUBLIC KNOWLEDGE PROJECT
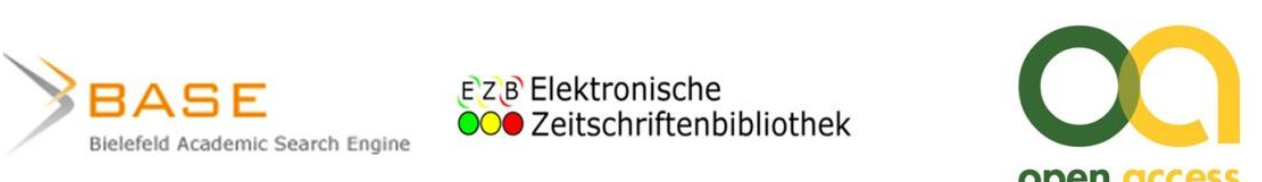

open access

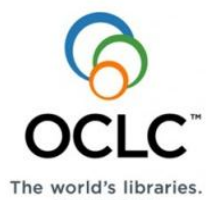

Connected.
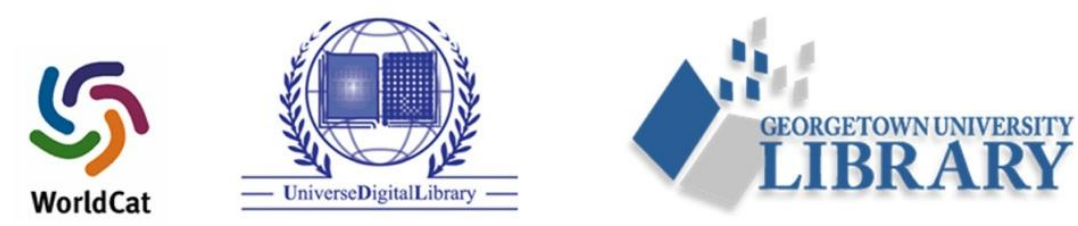